\title{
A IMPORTÂNCIA DOS RELATÓRIOS CONTÁBEIS NO PROCESSO DE GESTÃO DAS ORGANIZAÇÕES: UM ENSAIO TEÓRICO
}

Irene Caires da Silva, Luiz Roberto Darben, Thais Rubia Ferreira Lepre, Norrane Oliveira Prudente, Alesson Neres De Oliveira, Danilo Rodrigues De Oliveira, Larissa Silva Vieira Carvalho, Letícia Da Silva Hogera.

Universidade do Oeste Paulista - UNOESTE, Presidente Prudente, SP. E_mail: norrane_cso@hotmail.com.

\section{RESUMO}

Sobreviver sempre foi um desafio a qualquer tipo de negócio, porém nos últimos anos as dificuldades têm aumentado, devido principalmente a recessão econômica e ao aumento da concorrência, por isso as empresas precisam buscar diferenciação para manter-se competitivas no mercado. E a contabilidade pode ser muito útil para este fim, principalmente através da contabilidade gerencial, que fornece relatórios que possibilitam que a tomada de decisão seja assertiva. No entanto, grande maioria das empresas, principalmente as de micro porte apenas tem estes demonstrativos para cumprir com as obrigações legais, e não utilizam para seu verdadeiro fim, que é subsidiar a tomada de decisão. Justificando a importância deste estudo, que visa discutir esta questão, tendo em vista que tem como objetivo identificar quais demonstrativos contábeis devem ser utilizados para a tomada de decisões e como o mau uso destes pode prejudicar financeiramente qualquer negócio. E para alcança-lo utilizou abordagem qualitativa, tendo a pesquisa bibliográfica como único instrumento de coleta de dados. Os resultados mostram que a contabilidade gerencial é o apoio que qualquer empresário precisa para sobreviver no mercado, ao passo que possibilita planejamento baseado na realidade financeira do negócio. Palavras-chave: Contabilidade Gerencial. Sobrevivência. Tomada de Decisão. Empresas. Relatórios Contábeis.

\section{THE IMPORTANCE OF ACCOUNTING REPORTS IN THE MANAGEMENT PROCESS OF ORGANIZATIONS: A THEORETICAL TEST}

\begin{abstract}
Surviving has always been a challenge for any type of business, but in recent years the difficulties have increased, mainly due to economic recession and increased competition, so companies need to seek differentiation to remain competitive in the market. And accounting can be very useful for this purpose, especially through managerial accounting, which provides reports that enable decision making to be assertive. However, most companies, especially micro-sized companies only have these statements to comply with legal obligations, and do not use for their true purpose, which is to subsidize decision-making. Justifying the importance of this study, which aims to discuss this issue, given that it aims to identify which accounting statements should be used for decision making and how the misuse of these can financially harm any business. And in order to reach it, he used a qualitative approach, with bibliographic research being the only instrument for collecting data. The results show that manage
\end{abstract}


rial accounting is the support that any entrepreneur needs to survive in the market, while allowing planning based on the financial reality of the business.

Keywords: Managerial Accounting. Survival. Decision Making. Companies. Accounting Reports.

\section{INTRODUÇÃO}

O cenário econômico atual, tem trazido grandes desafios a sobrevivência dos negócios no mercado. O aumento da inflação somado a queda do consumo, fez emergir entre as empresas a necessidade de buscar diferenciação, tendo em vista que a concorrência aumentou consideravelmente nos últimos anos e o consumidor torna-se cada dias exigente, pois tem informação e uma diversidade de opções. Diante desse cenário cerca de $60 \%$ das empresas não sobrevivem aos cinco primeiros anos.

Desse modo, um fator determinante para a sobrevivência das mesmas, além da satisfação dos clientes, é o uso correto da contabilidade gerencial, como diferencial competitivo. Além de preencher requisitos obrigatórios por lei, a contabilidade gerencial busca tornar acessíveis determinadas informações financeira que fazem toda a diferença na manutenção de uma empresa no mercado, facilitando a tomada de decisões de gestores, como auxilio. Através dos relatórios é possível aumentar o grau de competitividade nas empresas, visto que sua composição é bastante precisa e evidente, trazendo informações necessárias para averiguação entre empresas rivais e possíveis mudanças necessárias no diaa- dia do negócio, para que sejam alcançados melhores resultados.

É notável, portanto, quando uma organização faz o uso correto dos relatórios gerenciais, pois além de agregarem valor, trazem informações oportunas, seguido de sucesso e diferencial na vida da empresa, com estratégias inovadoras, melhorando sua eficiência.

Todavia, veremos a importância dos relatórios contábeis para tomada de decisões nas empresas, muitas organizações ainda os utilizam apenas para cumprirem as exigências da lei, acabando por não entender a verdadeira realidade do negócio, ou seja, falta conhecimento a respeito da utilidade dos mesmos, justificando assim a importância deste artigo que auxiliara empreendedores e jovens contadores que buscam conhecimento sobre o uso da contabilidade gerencial.

O presente artigo tem como objetivo principal identificar quais demonstrativos contábeis devem ser utilizados para a tomada de decisões e como o mau uso destes pode prejudicar financeiramente qualquer negócio.

\section{METODOLOGIA}

Para atingir o objetivo deste artigo foi realizada uma pesquisa bibliográfica, onde se buscou informações em livros, artigos científicos, revistas especializadas, sites oficiais entre outros.

A pesquisa bibliográfica foi elaborada com base em material já publicado, esta modalidade de pesquisa inclui livros, revistas, teses, dissertações e anais de eventos científicos (GIL, 2017).

Para tanto, compreende-se que a presente pesquisa quanto ao objeto é de abordagem qualitativa em que a pesquisa bibliográfica será o instrumento utilizado para 
coletar informações sobre os benefícios das empresas que utilizam adequadamente as ferramentas de contabilidade gerencial.

\section{DISCUSSÃO}

A contabilidade é uma ciência que utiliza como instrumento de estudo o patrimônio das organizações, onde é possível ter o controle e registros de todas as atividades da entidade, utilizando os relatórios contábeis, demonstrativos econômicos e financeiros. Através da análise desses é possível medir os resultados da empresa e dar direção nos processos de tomada de decisão.

Desse modo, todas as informações de movimentação mensuráveis são registradas pela contabilidade, pois são esses registros que vão resumir os relatórios contábeis. "A Contabilidade é o instrumento que fornece o máximo de informações uteis para a tomada de decisões dentro e fora da empresa. Ela é muito antiga e sempre existiu para auxiliar as pessoas a tomarem decisões" (MARION, 2015, p. 68).

Desse modo, é a contabilidade quem vai fornecer todos os registros e dados essenciais para que o gestor possa avaliar a situação da empresa e tomar as decisões cabíveis.

Uma boa gestão esta ligada diretamente com uma contabilidade feita adequadamente.

De acordo com estudos realizados por ludícibus (2015, p. 7).

O objetivo básico da Contabilidade, portanto, pode ser resumido no fornecimento de informações econômicas para os vários usuários, de forma que propiciem decisões racionais. Não conhecemos suficientemente, ainda, todos os detalhes de cada modelo decisório de cada usuário. Enquanto isso não for conseguido, não poderemos atender igualmente bem, em todo e qualquer tempo, a todos os usuários.

Com as inúmeras alterações que a atualidade nos traz, ter um diferencial competitivo tornou-se fundamental para sobreviver no mundo dos negócios. Com isso cada vez mais os gestores buscam informações seguras para basearem suas decisões, e conseguirem acompanhar as inúmeras situações que a nova dinâmica do mercado traz.

Mas logo se deparam com outra situação, será que apenas juntar informações é suficiente nos dias atuais?

Estamos na era da tecnologia, onde tudo está ligada e nada passa despercebido. Controlar e acompanhar o que ocorre dentro de uma organização tem se tornado cada vez mais complexo, não basta simples planilhas como fluxo de caixa, por exemplo, o mundo dos negócios está exigindo muito além. Teremos que estar ligados e atentos as todas as modificações que estão surgindo em função da era da tecnologia.

E como grande diferencial competitivo a contabilidade gerencial vem crescendo em grande escala, por ter fundamental importância para a segurança e organização de uma empresa, cada vez mais gestores tem se apoiado em seus relatórios gerencias obtidos em sistemas integrados, para analisar, interpretar e tomar decisões. "A contabilidade gerencial mudou o foco da contabilidade, passando dos registros e análise das transações financeiras para a utilização da informação para decisões, afetando o futuro" (PADOVEZE, 2007, p.9)". Baseando-se nos relatórios gerenciais o gestor pode comparar o desempenho real de sua empresa, com relatórios que atendam as suas necessidades, bem como controlar e conhecer seus maiores competidores. 


\section{RESULTADOS}

Como ferramenta de gestão a contabilidade oferece vários ramos, dentre eles destacam-se alguns tipos como, por exemplo: A contabilidade financeira, que trata-se de um método para auxiliar, organizar e gerir o negócio. Mas temo como foco os relatórios gerenciais para que possam auxiliar o processo de gestão das organizações.

A contabilidade gerencial trata-se do ramo mais utilizado nos dias atuais, nela se encontra um número diversificado de sistemas operacionais que preenchem todas as necessidades informacionais sobre o andamento da empresa, necessários para tomada de decisões, considerando patrimônio, controle operacional, econômico e financeiro.

Dentro do contexto empresarial, volta-se para o usuário interno, alimentando diferentes planilhas, relatórios e outras ferramentas que fornecem dados para comparações, elaboração de orçamento, correta definição do preço dos produtos ou serviços e até mesmo na criação de metas e objetivos da empresa.

Segundo ludícibus (apud PADOVEZE, 2010, p. 33):

A Contabilidade Gerencial pode ser caracterizada, superficialmente, como um enfoque especial conferido a várias técnicas e procedimentos contábeis já conhecidos e tratados na contabilidade financeira, na contabilidade de custos, na análise financeira de balanços etc., colocados numa perspectiva diferente, num grau de detalhe mais analítico ou numa forma de apresentação e classificação diferenciada, de maneira a auxiliar os gerentes das entidades em seu processo decisório.

Com a utilização da contabilidade gerencial, é possível comparar a empresa com sua concorrência, utilizando dados de mercado para entender melhor o contexto em que a mesma se encontra, através de previsões e tendências para projetar o futuro de suas atividades como um todo, na busca de êxito econômico.

O objetivo básico da informação contábil é ajudar alguém a tomar decisões [...] Independente de quem está tomando a decisão, o entendimento da informação contábil propicia a tomada de uma decisão melhor e mais bem fundamentada. (HORNGREN; SUNDEN; STRATTON, 2014, p.4).

Neste sentido, existem diversos sistemas que auxiliam o gerenciamento da empresa, tanto no sentido financeiro, como no econômico, entre estes, temos o sistema de informação contábil destinado a prover as informações de natureza econômica e financeira através de ferramentas citadas adiante e relatórios.

As principais ferramentas utilizadas nas organizações são os demonstrativos contábeis sendo eles: balanço patrimonial, que evidencia num determinado período, a situação patrimonial e financeira da entidade; Fluxo de caixa, que apresenta a arte de gerenciar o dinheiro contido no caixa da empresa, o recebido e o gasto.

Temos também controle de estoque, essencial para domínio da movimentação do estoque na empresa, numa empresa micro ou pequena, isso se torna fácil de acompanhar, entretanto numa empresa de grande porte o controle de estoque tem que ser bem controlado para que possa facilitar o processo de gestão.

Já a folha de pagamento, que apresenta o custo do funcionário na empresa, em outras palavras se o mesmo tem valido a pena, assim como uma projeção de folha futura, reajustes por tempo de serviço, entre outros cálculos importantes que compõem os salários do corpo funcional de uma empresa.

Desse modo, temos controle de gastos gerais, de uma forma necessária, mostra os gastos corriqueiros que acontecem no mundo empresarial. 
Segundo Joaquim (apud HENRIQUE, 2008, p. 8) "as ferramentas de contabilidade gerencial são: Balanço Patrimonial, Demonstração do Resultado, Elaboração de Índices Financeiros e Econômicos (através do Balanço Patrimonial e da Demonstração de Resultado) e a Demonstração de Fluxo de Caixa". Para que todos os sistemas funcionem por meio das ferramentas acima citadas é importante que ocorra planejamento para a produção dos relatórios e controle para que sejam entregues em datas oportunas. Assim como o próprio princípio contábil de oportunidade, que determina que o processo de mensuração e apresentação dos componentes patrimoniais precisa ser feitas com integridade e tempestividade. Necessitando atender os níveis empresariais, administrativo e de informação da entidade.

Atualmente tem-se um número inimaginável de ferramentas modernas, algumas ainda não implantadas em todos os países, que da mesma forma buscam apresentar um aspecto da empresa em sistemas orçamentais, analise financeira, custeio e entre outras.

Esse diferencial não é um ponto positivo apenas, mas uma questão de necessidade para a sobrevivência de empresas do cotidiano.

Dessa forma é possível uma observação, de modo que as ferramentas utilizadas hoje como utensílios em uma gestão atual de empresas, instituições de terceiro setor, instituições bancárias, entre outras, não se compara com os mecanismos utilizados antigamente, quando o fator primordial da contabilidade nas empresas era relacionado apenas a tributos e ao operacional, para fins de registros, sem a interação na administração com uma força como é atualmente.

\section{CONCLUSÃO}

Portanto, foi possível concluir que a contabilidade gerencial é a principal ferramenta de gestão que se tem conhecimento, e seu mau uso pode trazer consequências irreversíveis para empresas de qualquer segmento ou porte. Através dos dados coletados ao longo deste artigo, foi possível confirmar que a contabilidade gerencial, sua forma de gerar informações para auxiliar quem gerencia e administra.

O mau uso dessas ferramentas resulta em um gerenciamento inadequado, com falta de planejamento, onde há grande desinteresse sobre sua importância por conta do tempo para atingir tais objetivos, que certamente afastariam a empresa do erro e obteria estratégias melhores, mas que por fim essas ferramentas de gerenciamento são ignoradas, pois há ainda o pensamento antigo onde a contabilidade ainda é vista apenas para exigências governamentais de pagamentos de obrigações fiscais. (MARION, 2010, p. 30).

Observaram-se resultados positivos alcançados com o uso das ferramentas gerenciais nas organizações, sendo um diferencial competitivo para quem faz uso no processo de gestão. O que tem motivados muitos gestores fazerem um uso dos relatórios na tomada de decisões.

E por fim, como esses relatórios influenciam positivamente para a sobrevivência de um mercado competitivo pede-se algo diferente, a contabilidade gerencial é o apoio para qualquer empresário estruturar e entender a sua empresa de um modo geral, possibilitando planejamentos baseado em um estudo real. 


\section{REFERENCIAS}

ADMINISTRADORES. O que é contabilidade afinal? 2014 Disponível em: <http://www.administradores.com.br/artigos/negocios/o-que-e-contabilidadeafinal/80221> Acesso em: 6 mai. 2018

BLB. Conceitos da contabilidade rural. Disponível em: <http://portal.blbbrasilescoladenegocios.com.br/o-que-e-contabilidade-rural/>. Acesso em: 22 mar. 2018.

CLÓVIS, L. Sistemas de informações contábeis: fundamentos e análises. 7. ed. São Paulo: Atlas, 2015.

COACHING FINANCEIRO. Conceito de contabilidade Financeira. Disponível em: <BLB. A contabilidade financeira. http://portal.blbbrasilescoladenegocios.com.br/contabilidadefiscal-como-funciona>. Acesso em: 22 mar. 2018.

HORNGREN; SUNDEM; STRATTON. Contabilidade Gerencial. 12. ed. 2004.

IDALBERTO, C. Introdução a teoria geral da administração. 9. ed. Barueri: Manole, 2014. IUDÍCIBUS, S. Teoria da Contabilidade. 11. ed. São Paulo: Atlas S.A., 2015

GIL, A. C. Como elaborar projetos de pesquisa. 6 ed. São Paulo: Atlas, 2017. Disponível em: https://integrada.minhabiblioteca.com.br. Acesso em: 08 agostos 2018.

MARION, J. C. Contabilidade Básica. 11. ed. São Paulo: Atlas, 2015

PADOVEZE, C. Contabilidade Gerencial: um enfoque em sistema de informação contábil. 7. ed. São Paulo: Atlas, 2010.

PORTAL DA CONTABILIDADE. Contabilidade Publica. Disponível em: <http://www.portaldecontabilidade.com.br/ tematicas/contabilidadepublica.htm. Acesso em: 22 mar. 2018.

TEIXEIRA, A. A utilização de ferramentas de contabilidade gerencial nas empresas do estado do Espírito Santo. 2007. Disponível em: <http://www.fucape.br/_public/producao_cientifica/2/Aridelmo\%2020a\%20utilizacao\%20de\%20ferramentas.pdf >. Acesso em: 10 ago. 2018 